\title{
Comparison of Bupivacaine injection versus normal saline in port sites \& intraperitoneal spray for postoperative pain in laparoscopic cholecystectomy.
}

1. FCPS, MSc (Pain Medicine) Associate Professor Anesthesia Shaikh Zayed Hospital, Lahore. 2. FCPS

Senior Registrar Anesthesia Jinnah Hospital, Lahore.

3. MBBS

Women Medical Officer

RHC, Sukhekhi Mandi, Hafizabad.

4. MS

Senior Registrar Anesthesia

Shaikh Zayed Hospital, Lahore.

Correspondence Address:

Dr. Hajra Shuja

Department of Anesthesia

Jinnah Hospital, Lahore.

hajrashuja1@gmail.com

Article received on:

22/12/2020

Accepted for publication

$28 / 05 / 2021$

\begin{abstract}
Syed Mehmood Ali', Hajra Shuja ${ }^{2}$, Mehak Adil ${ }^{3}$, Sadaf Bokhari ${ }^{4}$
ABSTRACT... Objective: To compare mean pain using bupivacaine injection versus normal saline in port sites \& intraperitoneal spray in laparoscopic cholecystectomy. Study Design: Randomized Controlled Trial. Setting: Department of Anesthesia, Shaikh Zayed Hospital, Lahore. Period: October 2, 2018 to April 2, 2019. Material \& Methods: Laparoscopic cholecystectomy patients were allocated to obtain either bupivacaine $0.25 \%$ or regular saline $(\mathrm{N} / \mathrm{S})$ randomly by lottery method. In bupivacaine group-A, $15 \mathrm{ml}$ of $0.25 \%$ bupivacaine spray on gall bladder bed, dissection surface and in ports area after surgery. In normal saline group-B received $15 \mathrm{ml}$ of normal saline in the same area and ports after surgery. Pain was measured on VAS as per operational definition. All the data was entered with SPSS v25.0 and analyzed. A t-test study was used to evaluate the mean pain for both groups at 3 hours, 6 hours, 12 hours, and 24th hours. In order to address the effect modifiers, the data was stratified for age, gender, and BMI (obese, non-obese). The independent t-test sample after stratification was used taking p-value 0.05 as relevant. Results: A total of 60 patients were included for elective laparoscopic cholecystectomy. In group-A, mean pain score was $3.33 \pm 0.81$ and $4.37 \pm 1.16$ in group-B, which is statistically significant with a p-value of 0.0002 . Conclusion: This study demonstrates that bupivacaine spray at the surgical bed and in ports site in elective laparoscopic cholecystectomy result in significant lowering of the intensity of postoperative abdominal and shoulder pain.
\end{abstract}

Key words: Bupivacaine, Laparoscopic Cholecystectomy, Pain Score.

Article Citation: Ali SM, Shuja H, Adil M, Bokhari S. Comparison of Bupivacaine injection versus normal saline in port sites \& intraperitoneal spray for postoperative pain in laparoscopic cholecystectomy. Professional Med J 2021; 28(7):1028-1032. https://doi.org/10.29309/TPMJ/2021.28.07.6292

\section{INTRODUCTION}

There are a number of significant benefits of laparoscopic cholecystectomy in upper gastrointestinal procedure e.g. an upper abdominal incision is avoided as an open approach for the treatment of benign gallbladder disease. ${ }^{1-2}$ Preventing this incision reduces postoperative respiratory complications, wound pain and high medical costs. ${ }^{3}$ Laparoscopy cholecystectomy has become the alternative treatment for gall bladder surgery. ${ }^{3}$ In contrast with the conventional open procedure, laparoscopy cholecystectomy has become the treatment with less postoperative discomfort, decreased analgesic intake, improved recovery and shorter hospital stay. Nevertheless, the severity of postoperative abdominal and shoulder pain remains significant, which in a large number of patients restricts laparoscopy cholecystectomy as a day case surgery. ${ }^{4}$ Tissue damage caused by surgical incisions, removal of the gall bladder from the liver bed, stretching of the nerve endings, and inflammation of the diaphragm by carbon dioxide are the pathophysiological mechanisms which contribute to postoperative pain. ${ }^{4}$

The primary cause of respiratory dysfunction following surgery of upper abdomen is postoperative pain. Post-operative pain management and respiratory function restoration are preferred with epidural analgesia, but related complications and contraindications may be limited in outpatient surgery. ${ }^{5}$ Uncontrolled postoperative pain result in tachycardia, high blood pressure, nausea, vomiting, and ileus. Therefore, pain relief and patient satisfaction are essential in the early postoperative period, because of increased demand and side effects 
of analgesics may delay discharge and increase hospital stay as well as cost. ${ }^{6}$ The adequacy of postoperative pain management is one of the main factors in deciding if a patient can be safely discharged and has a significant impact on the patient's normal daily activities. ${ }^{6}$

An ideal analgesic agent should start quickly and have a long half-life, delivering analgesic activity equivalent or greater than opioids such as morphine without or least side effects. ${ }^{6}$ Bupivacaine is a long-acting, 2.5-3.5 h half-life local anesthetic which is recorded to regulate pain for mean 6-hour duration. ${ }^{6}$

In a study, bupivacaine injection in sites and intraperitoneal spray were compared to normal saline in laparoscopic cholecystectomy. They reported the mean postoperative pain in abdominal and in shoulder region at 3 hours, 6hours, 12 hours, and 24 hour after surgery in bupivacaine group was $4.98 \pm 1.07$ and in normal saline group was $6.56 \pm 0.86$, p-value $<0.001 .{ }^{7}$ This study was designed to compare the bupivacaine injection in sites \& intra-peritoneal spray versus normal saline in laparoscopic cholecystectomy in local population. There was no local study available and a study done in other population reported less mean pain using Bupivacaine. If we also find less pain in Bupivacaine group, then in future it could be used to reduce post-operative abdominal and shoulder pain. This study will help in future for reduction in pain, analgesia related side effects and early discharge of patients.

\section{MATERIAL \& METHODS}

The study was conducted at Department of Anesthesia, Shaikh Zayed Hospital, Lahore from October 2, 2018 to April 2, 2019 approval from ethics committee was obtained from institutional ethics committee. The inclusion criteria was ASA status I and II patients, age between 18-60 years, both genders, indication for chronic cholecystitis and gall-bladder stone. The exclusion criteria was cases having history of opioid addiction (as a result of tolerances to ordinary narcotic or anesthetic doses used for pain alleviation can be confused by medications or substance abuse) and history of persistent analgesic intake. Sample size 60(30 patients in each group) was estimated. The mean postoperative abdominal pain and shoulder pain at 3 hours, 6 hours, 12 hours, and 24 hour after surgery, in Bupivacaine group-A as $4.98 \pm 1.07$ and in normal saline group-B as $6.56 \pm 0.86$. $^{7}$ We used $80 \%$ power of test and $95 \%$ confidence level.

Patients were allocated by the randomly used lottery method to obtain either bupivacaine or normal saline in laparoscopic cholecystectomy. Also in both groups the routine anesthetic medications were used. Standard 4 port laparoscopic cholecystectomy for all patients was performed by a single surgical team and pressure limited from 10 to $15 \mathrm{mmHg}$ according to the patient's body weight was executed after insertion of needle in a supra-umbilical zone.

In bupivacaine group-A, $15 \mathrm{ml}$ of $0.25 \%$ bupivacaine was sprayed all around the gall bladder bed and dissection surface area after completion of cholecystectomy and removal of gallbladder. After removing the ports, $0.25 \%$ bupivacaine was in-filtrated into the site of incisions of ports $(10 \mathrm{ml}$ in port-1, $10 \mathrm{ml}$ in port-2, and $5 \mathrm{ml}$ in port-3 and $5 \mathrm{ml}$ in port-4). The normal saline group-B received in the same regimen and in the same area and in ports.

Pain was measured at 3 hours, 6 hours, 12 hours, and 24th hours after surgery using visual analogue scale ranged from $0-10$, where 0 showed no pain and 10 showed worst pain. Shoulder pain was also measured. Patients who developed pain (VAS score $\geq 6$ ) received intravenous $100 \mathrm{mg}$ tramadol.

All collected data was entered and analyzed using SPSS version 25.0. Frequency and percentage were used for categorical data such as gender. Mean \pm S.D was calculated for quantitative data like patient's age and pain. A t-test study was used to evaluate the mean pain for both groups at $3,6,12$ \& 24th hours. In order to treat effect modifiers, the data was stratified by age, gender and BMI (obese, non-obese), and the p-value 0.05 were applied after the stratification by using independent t-test. 


\section{RESULTS}

In this study, 60 patients were enrolled for elective laparoscopic cholecystectomy for treatment of chronic cholecystitis and gall bladder stone. Patients were allocated to either obtain the bupivacaine $0.25 \%$ or normal saline.

The pain intensity was assessed at fixed interval at $3 \mathrm{hrs}, 6 \mathrm{hrs}, 12 \mathrm{hrs}$ and $24 \mathrm{hrs}$ postoperatively. The mean pain score was $3.33+0.80$ for bupivacaine group-A and from $4.36+1.16$ for the normal saline group-B and the remaining mean score was show in Table-l. There was statistically significant difference in pain at $12 \mathrm{hrs} \& 24 \mathrm{hrs}$. Three patient in study group and 2 patients in control group had shoulder tip pain $(p>0.05)$.

In bupivacaine group-A, $18(60 \%)$ patients were male and $12(40 \%)$ were female, while $17(56.7 \%)$ as male and $13(43.3 \%)$ as female in normal saline group-B. In bupivacaine group-A, 10(33.3\%) patients were in 18-30 years age group, while $9(30.0 \%)$ and $11(36.7 \%)$ were in $31-45$ years and $>45$ years age groups respectively. In normal saline group-B, $11(36.7 \%)$ patients were in $18-30$ years age group, while $14(46.7 \%)$ and $5(16.7 \%)$ were in $31-45$ years and $>45$ years age groups respectively.

In bupivacaine group-A, 3(10\%) patients were obese and $27(90 \%)$ were non-obese. In normal saline group-B, 4(13.3\%) patients were obese and $26(86.7 \%)$ were non-obese. In bupivacaine group-A, mean pain score was $3.33 \pm 0.81$ and $4.37 \pm 1.16$ in normal saline group- $B$, which is statistically significant with a p-value of 0.0002 . There was no significant difference between obese patients and age $>45$ years. $(P$ value $>0.05)$ Shoulder pain was also show with time interval and intervention status was statistically significant with groups $(P \leq 0.05)$.

\begin{tabular}{|c|c|c|c|c|c|}
\hline \multirow{3}{*}{ Mean pain at 3 hour } & Groups & $\mathbf{N}$ & Mean & Std. Deviation & P-Value \\
\hline & Bupivacaine & 30 & 9.23 & 0.91 & \multirow{2}{*}{0.0006} \\
\hline & Normal saline & 30 & 10.36 & 1.12 & \\
\hline \multirow[t]{2}{*}{ Mean pain at 6 hour } & Bupivacaine & 30 & 6.01 & 0.39 & \multirow{2}{*}{0.00001} \\
\hline & Normal saline & 30 & 8.32 & 1.39 & \\
\hline \multirow[t]{2}{*}{ Mean pain at 12 hour } & Bupivacaine & 30 & 4.62 & 0.63 & \multirow{2}{*}{0.00005} \\
\hline & Normal saline & 30 & 6.09 & 1.10 & \\
\hline \multirow[t]{2}{*}{ Mean pain score after 24 hours } & Bupivacaine & 30 & 3.33 & 0.80 & \multirow{2}{*}{0.0002} \\
\hline & Normal saline & 30 & 4.36 & 1.16 & \\
\hline
\end{tabular}

Table-I. Comparison of pain score in both groups

\begin{tabular}{|c|c|c|c|c|c|c|}
\hline \multirow{5}{*}{$\begin{array}{l}\text { Pain at 24th hours } \\
\text { (VAS) }\end{array}$} & Gender & Groups & $\mathbf{n}$ & Mean & Std. Deviation & P-Value \\
\hline & \multirow{2}{*}{ Male } & Bupivacaine & 18 & 3.22 & 0.94 & \multirow{2}{*}{0.014} \\
\hline & & Normal saline & 17 & 4.06 & 0.97 & \\
\hline & \multirow{2}{*}{ Female } & Bupivacaine & 12 & 3.50 & 0.52 & \multirow{2}{*}{0.004} \\
\hline & & Normal saline & 13 & 4.77 & 1.30 & \\
\hline
\end{tabular}

Table-II. Stratification of pain score after 24 hours in both groups with respect to gender

\begin{tabular}{|c|c|c|c|c|c|c|}
\hline \multirow{7}{*}{$\begin{array}{l}\text { Pain at 24th hours } \\
\text { (VAS) }\end{array}$} & Age Groups & Groups & $\mathbf{N}$ & Mean & Std. Deviation & P-Value \\
\hline & \multirow{2}{*}{$18-30$ years } & Bupivacaine & 10 & 3.30 & 0.67 & \multirow{2}{*}{0.002} \\
\hline & & Normal saline & 11 & 4.82 & 1.17 & \\
\hline & \multirow{2}{*}{$31-45$ years } & Bupivacaine & 9 & 3.22 & 0.83 & \multirow{2}{*}{0.019} \\
\hline & & Normal saline & 14 & 4.36 & 1.15 & \\
\hline & \multirow{2}{*}{$>45$ years } & Bupivacaine & 11 & 3.45 & 0.93 & \multirow{2}{*}{0.906} \\
\hline & & Normal saline & 5 & 3.40 & 0.55 & \\
\hline
\end{tabular}

Table-III. Stratification of pain score after 24 hours in both groups with respect to age 


\begin{tabular}{|c|c|c|c|c|c|c|}
\hline \multirow{4}{*}{$\begin{array}{l}\text { Pain at 24th hours } \\
\text { (VAS) }\end{array}$} & Body Mass Index & Groups & $\mathbf{n}$ & Mean & Std. Deviation & P-Value \\
\hline & \multirow{2}{*}{ Obese } & Bupivacaine & 3 & 4.33 & 0.58 & \multirow{2}{*}{0.673} \\
\hline & & Normal saline & 4 & 4.75 & 1.50 & \\
\hline & Non-obese & Normal saline & 26 & 4.31 & 1.12 & 0.0002 \\
\hline
\end{tabular}

Table-IV. Stratification of pain score after 24 hours in both groups with respect to BMI

\section{DISCUSSION}

In this analysis, effects of Bupivacaine injection were determined on postoperative abdominal and shoulder pain in elective laparoscopic cholecystectomy. The magnitude of the pain in bupivacaine relative to the normal saline groups was considerably lower. Alper et al. ${ }^{8}$, compared the efficacy of levo-bupivacaine and normal saline in alleviating post-operative pain after laparoscopic cholecystectomy. Administered intraperitoneally to the hepato-diaphragmatic lodge and above the gallbladder directly after pneumoperitonea, $40 \mathrm{~mL}$ levo-bupivacaine 0.25 percent showed useful results after laparoscopic cholecystectomy and decreased postoperative rescue analgesic needs, with excellent patient satisfaction. There were no risks or side effects associated with the use of levobupivcaine.

Over the intercostal or interpleural route Vieira et al. employed $0.5 \%$ bupivacaine $(100 \mathrm{mg}$ ) and identified an average analyses time of 505 minutes in the interplueral group and 620 minutes for the intercostal group, without any important statistical gap. ${ }^{9}$ Jabbour-Khoury et al. found that after elective laparoscopic cholecystectomy a multimodal approach to pain relief is better accomplished with a $40 \mathrm{~mL}$ of bupivacain $0.25 \%$ intraperitoneal and $200 \mathrm{mg}$ intravenous ketoprofen combinations. ${ }^{10}$

The effectiveness of intra-pleural bupivacain and opioid products was compared and better results were discovered in a Joshaghani et al., analysis in the bupivacain group. ${ }^{12}$ Hashemi et al., have also contrasted the efficacy of intra-peritoneal bupivacaine on placebo for post-laparoscopic cholecystectomy and observed that infiltrations of bupivacaine in the ports of laparoscopic cholecystectomy with liver/gall bladder are successful in post-operative pain relief. ${ }^{13}$
During the laparoscopic treatment there is a dispute over a major cause of discomfort. According to some clinical experts, the most frequent trigger of trocar placing through the abdominal wall is intraperitoneal dissection and insuflations of $\mathrm{CO} 2$, resulting in abdominal distension and prolongation of diaphragm. Early pain after laparoscopic cholecystectomy has been complicated by multiple pain components arising from different pain pathways, such as abdominal surgical trauma, intra-abdominal trauma caused by the elimination of the abdominal gall bladder.

\section{CONCLUSION}

This study demonstrates that bupivacaine spray at the surgical bed and in ports site in elective laparoscopic cholecystectomy result in significant lowering of the intensity of postoperative abdominal and shoulder pain. By this regimen in elective laparoscopic cholecystectomy a patient can faster return to his or her normal life, reduced analgesic consumption, shorter hospital stay and less medical cost.

\section{Copyright $\odot 28$ May, 2021.}

\section{REFERENCES}

1. Trastulli S, Cirocchi R, Desiderio J, Guarino S, Santoro A, Parisi A, et al. Systematic review and meta-analysis of randomized clinical trials comparing single-incision versus conventional laparoscopic cholecystectomy. British J Surg. 2013; 100(2):191-208.

2. Choi GJ, Kang $H$, Baek CW, Jung $Y H$, Kim DR. Effect of intraperitoneal local anesthetic on pain characteristics after laparoscopic cholecystectomy. World J Gastroenterol. 2015; 21(47):13386.

3. Yeh CN, Tsai CY, Cheng CT, Wang SY, Liu YY, Chiang $\mathrm{KC}$, et al. Pain relief from combined wound and intraperitoneal local anesthesia for patients who undergo laparoscopic cholecystectomy. BMC Surg. 2014; 14(1):28. 
4. Lin S, Hua J, Xu B, Yang T, He Z, Xu C, et al. Comparison of bupivacaine and parecoxib for postoperative pain relief after laparoscopic cholecystectomy: A randomized controlled trial. Int $\mathrm{J}$ Clin Experiment Med. 2015; 8(8):13824-9.

5. Basaran B, Basaran A, Kozanhan B, Kasdogan E, Eryilmaz MA, Ozmen S. Analgesia and respiratory function after laparoscopic cholecystectomy in patients receiving ultrasound-guided bilateral oblique subcostal transversus abdominis plane block: A randomized double-blind study. Int Med J Experiment Clinic Res. 2015; 21:1304-12.

6. Upadya M, Pushpavathi S, Seetharam KR. Comparison of intra-peritoneal bupivacaine and intravenous paracetamol for postoperative pain relief after laparoscopic cholecystectomy. Anesth Essays Res. 2015; 9(1):39-43.

7. Ali GA, Mehdi J, Behnam M, Abolfazl S, Shirzad N, Aidin YNJ, et al. Post-operative pain relief following bupivacaine injection in sites \& intra-peritoneal spray of laparoscopic cholecystectomy. J Pharmaceu Res Int. 2017; 19(4):1-7.

8. Alper I, Ulukaya S, Ertugrul V, MakayO, Uyar M, Balcioglu $\mathrm{T}$. Effects of intraperitoneal levobupivacaine on pain after laparoscopic cholecystectomy: A prospective, randomized, double-blinded study. Agri. 2009; $21(4): 141-5$.
9. Vieira AM, Schnaider TB, Brandao AC, CamposNeto JP. Comparative study of intercostal and interpleural block for postcholecystectomy analgesia. Rev Bras Anestesiol. 2003; 53(3):346-50.

10. Jabbour-Khoury SI, Dabbous AS, Gerges FJ, Azar MOS, Ayoub CM, Khoury GS. Intraperitoneal and intravenous routes for pain relief in laparoscopic cholecystectomy. JSLS. 2005; 9(3):316-21.

11. Castillo-Garza G, Diaz-Elizondo JA, Cuello-Garcia $\mathrm{CA}$, Villegas-Cabello $\mathrm{O}$. Irrigation with bupivacaine at the surgical bed for postoperative pain relief after laparoscopic cholecystectomy. JSLS. 2012; 16(1):105-11.

12. ZareJoshaghani M, MirhosseiniS, Hosseininasab S, Haji Esmaili M. Pain reduction amount after intra-pleural injection of bupivacaine versus opiums in upper abdominal surgeries. Shahid-Sadooghi Med Univ J. 2005; 13(4):26-9.

13. Hasehmi S, Naghibi $\mathrm{KH}$, Rahimi M, RaeiM, Nasirian B. Effect of intra-peritoneal administration of bupivacaine on morphine use after cholecystectomy. Gilan Med UnivJ. 2002; 11(43):5-10.

\begin{tabular}{|c|l|l|l|}
\hline \multicolumn{3}{|c}{ AUTHORSHIP AND CONTRIBUTION DECLARATION } \\
\hline Sr. \# & \multicolumn{1}{|c|}{ Author(s) Full Name } & Contribution to the paper & Author(s) Signature \\
\hline 1 & Syed Mehmood Ali & Write up, Data collection. \\
\hline 2 & Hajra Shuja & $\begin{array}{l}\text { Help in data collection, } \\
\text { write up and reviewing. } \\
\text { Write up, Literature review. }\end{array}$ \\
\hline 3 & Mehak Adil & Proof reading, Analysis. \\
\hline 4 & Sadaf Bokhari & Soja & \\
\hline
\end{tabular}

